\title{
Relative biological effectiveness of alpha particles and protons varies with biological criteria, and values are mutually correlated in thermal neutron exposure
}

\author{
Yasuo Ukai*1,2) and Atsushi Yamashita ${ }^{1,3)}$ \\ 1) Institute of Radiation Breeding, NIAS, MAFF, Hitachi-Ohmiya, Ibaraki 319-2293, Japan \\ 2) Present address: Tsuchiura, Ibaraki 300-0837, Japan \\ 3) deceased
}

We recently presented a method for simultaneous estimation of relative biological effectiveness (RBE) of alpha particles and protons. Here, we evaluate RBE for chlorophyll mutation rate and four $\mathrm{M}_{1}$ effects in thermal neutron exposure of barley (Hordeum vulgare L.) seeds. RBEs of both alpha particles and protons were low for germination rate, seedling height, and number of spikes, and high for seed fertility and mutation rate. Thus, $M_{1}$ effects are not necessarily accurate as a proxy for mutation rate in comparisons of different types of radiation. RBE of alpha particles for mutation rate was 130.3, much higher than values so far reported in plant materials. RBE of protons for mutation rate was 106.4; as far as we are aware, this is the first value reported for thermal neutron exposure of plant materials. RBEs of alpha particles and protons were significantly correlated $(r=0.939, P<0.05)$.

Key Words: relative biological effectiveness, boron addition effect, alpha particles, protons, thermal neutrons, chlorophyll mutation, Hordeum vulgare.

\section{Introduction}

Densely ionizing (high-LET [linear energy transfer]) radiations such as neutrons, alpha particles, protons and heavy ions generally have a greater biological effectiveness than sparsely ionizing (low-LET) radiation such as gamma-rays and X-rays in a variety of materials, including DNA (Goodhead 1999), Drosophila (Yoshikawa et al. 1999), mammals (Davis et al. 1970, Barendsen (1994), and plants (MacKey 1951, Bender 1970, Ukai 1986, 2006). The effectiveness of different forms of radiation is compared as relative biological effectiveness (RBE), defined as the ratio of an absorbed dose of radiation to the absorbed dose of reference radiation $\left(250 \mathrm{kVp} \mathrm{X}\right.$-rays or ${ }^{60} \mathrm{Co}$ gamma-rays) required to produce an equivalent biological effect in a particular organism or tissue.

Early studies by Conger and Giles (1950) showed that $99 \%$ of the total energy deposited in plant tissue exposed to thermal neutrons derives from three neutron capture reactions: ${ }^{10} \mathrm{~B}(\mathrm{n}, \alpha){ }^{7} \mathrm{Li},{ }^{14} \mathrm{~N}(\mathrm{n}, \mathrm{p}){ }^{14} \mathrm{C}$, and ${ }^{1} \mathrm{H}(\mathrm{n}, \gamma){ }^{2} \mathrm{H}$. Among these reactions, the first two are important in radiobiology and mutation breeding, since they emit charged heavy particles with high LET, viz. alpha particles and protons.

Recently, we presented a method for the simultaneous estimation of the RBE of alpha particles and protons (Ukai et al. 2009a, 2009b). RBEs were as high as 55.0 and 48.7,

Communicated by T. Nishio

Received December 28, 2009. Accepted April 6, 2010.

*Corresponding author (e-mail: luke154@jcom.home.ne.jp) respectively, in barley seeds immersed in various concentrations of ${ }^{10} \mathrm{~B}$-enriched boric acid and re-dried before thermal neutron exposure. Those values were derived from an $\mathrm{M}_{1}$ trait, seedling height. Seedling height can be measured within a short time, say 2 weeks, after sowing of irradiated seeds, and its reduction has long been used as a convenient index of the magnitude of radiation effects in plants, particularly cereals such as barley and rice. Although reduction in seedling height contributes only in part to the final radiobiological effect e.g. death, studies of the trait have thrown light on the mechanisms of many general phenomena in radiobiology, such as the effects of oxygen (Nilan et al. 1965), seed moisture content (Myttenaere et al. 1965), and boron addition (Nakai and Saito 1976).

However, for the purposes of mutation breeding, the effectiveness of radiation should be evaluated by mutation rate, not by $\mathrm{M}_{1}$ injury effect, since the aim is to achieve a mutation rate high enough for selection of practical mutants, and the magnitude of an $\mathrm{M}_{1}$ effect does not always represent the magnitude of the mutation rate. Hence, the estimation of RBE for mutation rate is essential for comparison of the utility of different types of radiation, although scoring of mutants in an $\mathrm{M}_{2}$ population large enough to give an estimate of mutation rate with good reproducibility is laborious and time-consuming. Earlier studies of RBE of alpha particles in thermal neutron exposure of plants focused mainly on seedling height (Ichikawa 1975) and chromosome aberrations (Ecochard and Oosterheert 1966, Moutschen et al. 1968), and only rarely on mutation rate: Matusmura et al. (1963) and Ikushima (1972) presented RBE values of alpha particles 
for chlorophyll mutation rate in thermal neutron exposure of seeds of Triticum species, but their results were not conclusive, since they did not analyze the boron content of seeds, but instead calculated it based on the assumptions of uniform distribution of boron atoms inside seeds and free entrance of boron into seeds together with water molecules. We found these assumptions to be invalid (Ukai et al. 2009b)

The aim here was to evaluate RBE of alpha particles from $\left.{ }^{10} \mathrm{~B}(\mathrm{n}, \alpha)\right)^{7} \mathrm{Li}$ and protons from ${ }^{14} \mathrm{~N}(\mathrm{n}, \mathrm{p}){ }^{14} \mathrm{C}$ for different $\mathrm{M}_{1}$ effects and chlorophyll mutation rate. $\mathrm{RBE}$ of protons for mutation rate in thermal neutron exposure of plant materials has never been reported, as far as we are aware. As $\mathrm{M}_{1}$ traits, we chose germination rate, number of spikes, seed fertility, and seedling height, because the effects of irradiation on these traits directly influence the amount of seeds available for growing an $\mathrm{M}_{2}$ population in which mutants are to be screened.

\section{Materials and Methods}

A six-rowed hulled barley, Hordeum vulgare L. cv. Chikurin Ibaraki 1, was used as the plant material in all experiments.

\section{Boron enrichment}

An aqueous solution of $1600 \mu \mathrm{g} \cdot \mathrm{g}^{-1}{ }^{10} \mathrm{~B}$-enriched boric acid $\left(\mathrm{H}_{3}{ }^{10} \mathrm{BO}_{3}\right)$ was prepared from boric acid (Eagle-Picher Industries Inc., Miami, OK, USA) in which the boron was composed of $91.746 \%{ }^{10} \mathrm{~B}$ and $8.254 \%{ }^{11} \mathrm{~B}$ (weight $\%$ ). Airdried seeds with ca. $10 \%$ moisture content were immersed in the solution in a $500-\mathrm{mL}$ glass beaker for $13 \mathrm{~h}$ at $20 \pm 1^{\circ} \mathrm{C}$. Five hundred seeds were used in each boron addition. The seeds were then washed with distilled and deionized water for a few minutes, and the surface water was blotted from the seeds. Seeds were then dried again to about $10 \%$ moisture content by exposure to a current of warm $\left(31 \pm 2^{\circ} \mathrm{C}\right)$, dry air for $16 \mathrm{~h}$. The seeds were kept over a saturated $\mathrm{NaClO}_{3}$ solution in a desiccator for 1 month, giving them a moisture content of $10.21 \% \mathrm{w} / \mathrm{w}$. They were then sealed in a small plastic bag to avoid any change of moisture content before and during irradiation.

Thermal neutron and gamma-ray irradiation and dosimetry

We prepared 500 and 1,000 seeds for each neutron dose with or without ${ }^{10} \mathrm{~B}$-enrichment, respectively. Thermal neutron exposure and dosimetry of neutron flux and contaminating gamma-rays were performed at the Research Reactor of Kyoto University, as described previously (Ukai et al. 2009a). Thermal neutron exposure was performed twice. In the first exposure, resting seeds and some of the ${ }^{10} \mathrm{~B}$ enriched seeds were exposed. The latter seeds were tested for germination rate and seedling height. The flux of thermal neutrons was $3.15 \times 10^{9} \mathrm{n} \mathrm{cm}^{-2} \mathrm{~s}^{-1}$, and the dose rate of contaminating gamma-rays was $10.52 \mathrm{~Gy} \cdot \mathrm{h}^{-1}$. The exposed doses were $0,0.094,0.189,0.378,0.567$ and 0.756 $\left(\times 10^{12} \mathrm{n} \mathrm{cm}^{-2}\right)$. In the second exposure, the remaining ${ }^{10} \mathrm{~B}$ - enriched seeds were exposed for examination of the number of spikes, seed fertility, and mutation rate. The flux of thermal neutrons was $4.03 \times 10^{9} \mathrm{n} \mathrm{cm}^{-2} \mathrm{~s}^{-1}$, and the dose rate of contaminating gamma-rays was $6.466 \mathrm{~Gy} \cdot \mathrm{h}^{-1}$. The exposed doses were $0,0.040,0.081,0.121,0.242$, and 0.484 $\left(\times 10^{12} \mathrm{n} \mathrm{cm}^{-2}\right)$.

For gamma-irradiation, we used a source of ${ }^{60} \mathrm{Co}$ in the gamma-room of the Institute of Radiation Breeding (National Institute of Agro-biological Resources, Ministry of Agriculture, Forestry and Fisheries), at $98 \mathrm{~Gy} \cdot \mathrm{h}^{-1}$. The exposed doses were $0,98,196,294,392,490$, and $588 \mathrm{~Gy}$ and the numbers of seeds employed for each dose were 1,000, 1,000, $1,000,2,000,3,000$ and 20,000, respectively.

Since $96 \%$ of the absorbed energy in the exposure of ${ }^{10} \mathrm{~B}$ enriched (using $1600 \mu \mathrm{g} \cdot \mathrm{g}^{-1}{ }^{10} \mathrm{~B}$-enriched boric acid) seeds to thermal neutrons are due to alpha particles from the reaction ${ }^{10} \mathrm{~B}(\mathrm{n}, \alpha)^{7} \mathrm{Li}$ (Ukai et al. 2009b), we refer for brevity to the exposure of ${ }^{10} \mathrm{~B}$-enriched seeds as alpha-particles exposure, and the exposure of resting seeds to thermal neutrons as neutron exposure. In the latter seeds, 9.53\%, 71.07\%, $19.40 \%$ of the absorbed energy are due to alpha particles, protons, and gamma-rays emitted from capture reactions $\left.{ }^{10} \mathrm{~B}(\mathrm{n}, \alpha)\right)^{7} \mathrm{Li},{ }^{14} \mathrm{~N}(\mathrm{n}, \mathrm{p}){ }^{14} \mathrm{C}$, and ${ }^{1} \mathrm{H}(\mathrm{n}, \gamma){ }^{2} \mathrm{H}$, respectively.

\section{Measurement of biological effects}

Germination rate, seedling height, and number of spikes: We sowed seeds with two replications (each replication consists of 100 seeds ) from each irradiation dose, either in a regular field (after gamma-ray exposure) or in an isolation field (after thermal neutron exposure). We counted seedlings 18 days after sowing and calculated the germination rate. We then measured the seedling height (the length from ground level to the tip of the first leaf) of $20 \mathrm{M}_{1}$ seedlings in each replication and calculated the mean seedling height. At flowering time in the following spring, we counted the spikes on each surviving plant.

Seed fertility: At maturity of the $\mathrm{M}_{1}$ plants, a spike was removed from each of 100 randomly chosen plants per dose, and the fertile and sterile seeds on each spike were counted.

Mutation rate per initial cell: In the next autumn, we grew $\mathrm{M}_{2}$ lines, each derived from an $\mathrm{M}_{1}$ spike. The number of seeds sown per line varied from 10 to 36 , depending on the seed fertility of the spike. During 20 to 50 days after sowing we scored chlorophyll mutants in the field almost every other day. Mutant frequency was calculated as the number of mutants divided by the total number of plants observed. The mutation rate per initial cell at the time of seed irradiation was then estimated as the mutant frequency $\times$ the inverse of the segregation ratio of a mutation ( 0.25$)$ according to Gaul (1960): i.e., mutation rate per initial cell $=$ mutant frequency $\times 4$. The cells of the shoot apex in a seed that develop into an inflorescence (spike) are called initial cells.

For each of the $M_{1}$ effects, the dose required to give 50\% of the value of the non-irradiated control (half reduction dose, $D_{50}$ ) was estimated from dose-response curves as previously 
Table 1. Chlorophyll mutation rate in gamma-irradiation, and neutron exposure of resting seeds, and neutron exposure of ${ }^{10} \mathrm{~B}$-enriched seeds (alpha-radiation)

\begin{tabular}{|c|c|c|c|c|c|}
\hline \multirow{2}{*}{ Dose } & \multicolumn{2}{|c|}{ Observed } & \multirow{2}{*}{$\begin{array}{c}\text { No. } \\
\text { mutants }\end{array}$} & \multirow{2}{*}{$\begin{array}{c}\text { Mutant } \\
\text { frequency }{ }^{a}\end{array}$} & \multirow{2}{*}{$\begin{array}{c}\text { S.E. }{ }^{b} \\
\%\end{array}$} \\
\hline & Lines & Plants & & & \\
\hline \multicolumn{6}{|c|}{ Gamma-rays (Gy) } \\
\hline 98 & 981 & 30,236 & 115 & 0.380 & 0.035 \\
\hline 196 & 1,191 & 30,795 & 296 & 0.961 & 0.056 \\
\hline 294 & 1,034 & 19,795 & 245 & 1.238 & 0.079 \\
\hline 392 & 1,244 & 21,047 & 419 & 1.991 & 0.096 \\
\hline 490 & 1,261 & 17,106 & 426 & 2.490 & 0.119 \\
\hline 588 & 1,407 & 15,770 & 502 & 3.183 & 0.140 \\
\hline
\end{tabular}

Thermal neutrons, resting seeds $\left(\times 10^{12} \mathrm{n} \cdot \mathrm{cm}^{-2}\right)$

\begin{tabular}{rrrlll}
5.1 & 1,889 & 42,954 & 621 & 1.445 & 0.058 \\
10.2 & 1,058 & 19,072 & 474 & 2.485 & 0.113 \\
15.2 & 583 & 8,242 & 286 & 3.470 & 0.202 \\
20.3 & 324 & 4,118 & 221 & 5.367 & 0.351 \\
\hline
\end{tabular}

Alpha-radiation, ${ }^{10}$ B-enriched seeds $\left(1600 \mu \mathrm{g} \cdot \mathrm{g}^{-1}\right)$

$\left(\times 10^{12} \mathrm{n} \cdot \mathrm{cm}^{-2}\right)$

\begin{tabular}{rrrrrr}
0.40 & 576 & 8,858 & 32 & 0.361 & 0.064 \\
0.81 & 576 & 8,392 & 57 & 0.679 & 0.090 \\
1.21 & 1,117 & 19,127 & 228 & 1.192 & 0.078 \\
2.42 & 355 & 5,779 & 95 & 1.644 & 0.167 \\
4.84 & 36 & 449 & 16 & 3.563 & 0.875 \\
\hline
\end{tabular}

${ }^{a}$ Percentage of chlorophyll mutants among the total number of $\mathrm{M}_{2}$ plants observed.

${ }^{b}$ Standard error.

shown (Ukai et al. 2009a). The dose required to give a mutation rate per cell of $8 \%\left(D_{8}\right)$ was similarly estimated.

\section{Results}

Mutation rate and mutation spectra of chlorophyll mutation

The frequency of chlorophyll mutants among total $\mathrm{M}_{2}$ plants observed increased linearly with dose in all radiation treatments. The maximum frequency of mutants was $3.183 \%$ by gamma-ray, $5.367 \%$ by neutron, and $3.563 \%$ by alpha-ray exposure. Mutation rates per cell were estimated by multiplying the frequencies of mutants with the inverse of the expected segregation ratio of mutants (0.25) according to Gaul (1957) and shown in Table 1.

Chlorophyll mutations included albina, xantha, viridis, alboviridis, tigrina and striata types. Since the phenotypic expression of the chlorophyll mutation types except albina depends on the growing stage of seedlings and the temperature of the screening field, and could not always be classified strictly, the mutants were divided simply into albina and the others. The numbers of albina vs. non-albina mutations were 311 vs. 327 by gamma-rays, 711 vs. 891 by thermal neutrons, and 126 vs. 302 by alpha-radiation. Alpha-ray exposure thus caused less albina mutation than gamma-ray and neutron exposure. Chi-square analysis of a $2 \times 3$ contingency table revealed that the difference in mutation spectra between alpha-radiation and the other treatments was highly
Table 2. Five biological effects of gamma-rays, thermal neutrons, and alpha-radiation

\begin{tabular}{|c|c|c|c|c|c|}
\hline $\operatorname{Dose}^{a}$ & $\begin{array}{l}\text { Germination } \\
\text { rate } \%\end{array}$ & $\begin{array}{c}\text { Seedling } \\
\text { height }^{b} \mathrm{~mm}\end{array}$ & $\begin{array}{c}\text { No. } \\
\text { spikes }^{c}\end{array}$ & $\begin{array}{c}\text { Seed } \\
\text { fertility }^{c} \%\end{array}$ & $\begin{array}{l}\text { Mutation } \\
\text { rate }^{d} \%\end{array}$ \\
\hline \multicolumn{6}{|c|}{ Gamma-rays (no ${ }^{10} \mathrm{~B}$ enrichment) ${ }^{e}$} \\
\hline 0 & 82.0 & 89.5 & 1.89 & 90.0 & 0.000 \\
\hline 98 & 80.8 & 84.9 & 1.89 & 78.5 & 1.520 \\
\hline 196 & 82.6 & 72.5 & 1.57 & 67.5 & 3.844 \\
\hline 294 & 71.0 & 65.3 & 1.21 & 57.1 & 4.952 \\
\hline 392 & 69.0 & 44.1 & 1.07 & 45.0 & 7.964 \\
\hline 490 & 59.7 & 31.2 & 0.77 & 30.2 & 9.960 \\
\hline 588 & 35.9 & 10.3 & 0.37 & 24.3 & 12.732 \\
\hline \multicolumn{6}{|c|}{ Neutrons (resting seeds) ${ }^{e}$} \\
\hline 0 & 80.4 & 89.5 & 2.92 & 84.0 & 0.00 \\
\hline 5.1 & 80.8 & 79.7 & 2.96 & 51.6 & 5.784 \\
\hline 10.2 & 81.6 & 57.5 & 2.27 & 30.5 & 9.940 \\
\hline 15.2 & 82.4 & 46.4 & 2.14 & 20.9 & 13.880 \\
\hline 20.3 & 71.6 & 25.1 & 1.49 & 12.3 & 21.468 \\
\hline 25.5 & 43.6 & 9.4 & 0.94 & - & - \\
\hline \multicolumn{6}{|c|}{ Alpha-radiation $\left({ }^{10} \mathrm{~B} \text {-enriched seeds }\right)^{f}$} \\
\hline 0 & 80.4 & 89.5 & 2.92 & 84.0 & 0.00 \\
\hline 0.094 & 80.4 & 84.4 & - & - & - \\
\hline 0.121 & $(79.4)^{g}$ & $(81.6)$ & 2.79 & 43.9 & 4.768 \\
\hline 0.189 & 80.1 & 71.6 & - & - & - \\
\hline 0.242 & $(72.6)$ & $(68.8)$ & 2.04 & 38.1 & 6.576 \\
\hline 0.378 & 64.6 & 49.0 & - & - & - \\
\hline 0.484 & $(57.4)$ & $(43.3)$ & 0.99 & 21.0 & 14.252 \\
\hline 0.567 & 53.9 & 39.8 & - & - & - \\
\hline 0.756 & 40.2 & 15.8 & - & - & - \\
\hline
\end{tabular}

${ }^{a}$ Dose: Gy for gamma-rays, $\times 10^{12} \mathrm{n} \cdot \mathrm{cm}^{-2}$ for thermal neutrons of ${ }^{10} \mathrm{~B}$ enriched and non-enriched seeds.

${ }^{b}$ Mean per number of seeds sown.

${ }^{c}$ Mean per number of surviving plants.

${ }^{d}$ Mutation rate per cell at time of irradiation $=$ frequency of mutants among total number of plants in $\mathrm{M}_{2} \times 4$.

${ }^{e}$ Air-dried resting seeds which were not immersed in water.

${ }^{f}$ Seeds were immersed in a $1600 \mu \mathrm{g} \cdot \mathrm{g}^{-1}$ boric acid solution for $13 \mathrm{~h}$ and re-dried before neutron exposure.

$g$ Values in parentheses were interpolated from the dose-response curves.

significant $(P<0.01)$, but that between gamma-rays and neutrons was not.

\section{Efficiency of mutation}

The values of the $4 \mathrm{M}_{1}$ effects and mutation rate per initial cell at different doses of gamma-ray, neutron, and alpha-ray exposure are presented in Table 2. The relationships between the value of each $\mathrm{M}_{1}$ effect and mutation rate are shown in Fig. 1-Fig. 4. In all of the $M_{1}$ effects, an increase in mutation rate was always accompanied by an increase in injurious effects.

However, the relationships differed between the effects. In germination rate (Fig. 1), seedling height (Fig. 2), and number of spikes (Fig. 3), the $\mathrm{M}_{1}$ injurious effect was always higher for gamma-rays than for neutrons at a given mutation rate, whereas in seed fertility (Fig. 4), there was little or no 
Mutation rate per cell (\%)

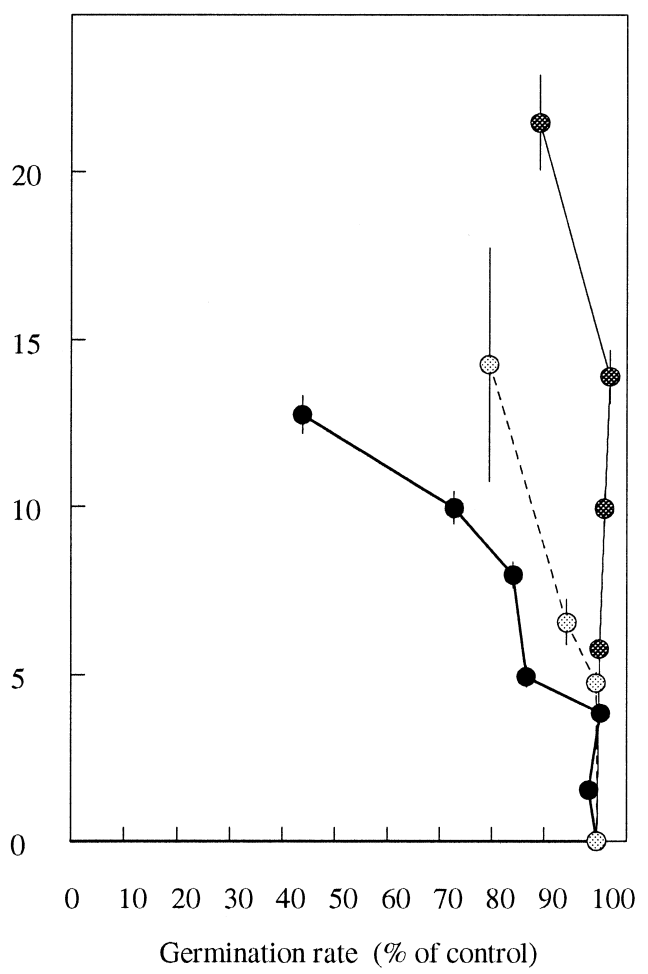

Fig. 1. Mutation rate as a function of germination rate. Solid, heavyshaded, and light-shaded circles stand for exposure of gamma-rays, neutrons and alpha particles. Vertical bars show the $95 \%$ confidence limits of chlorophyll mutation rate per initial cell.

difference. The relationship in alpha-ray exposure was intermediate between gamma-ray and neutron exposures in germination rate, similar to neutron exposure in seedling height, similar to gamma-irradiation in number of spikes, and close to both of the other radiation treatments in seed fertility.

\section{Boron addition effect (BAE)}

From dose-response curves, values of $D_{50}$ for $\mathrm{M}_{1}$ effects or $D_{8}$ for mutation rate were estimated for each form of radiation (Table 3). BAE was expressed as the ratio of $D_{50}$ of neutron exposure $\left(D_{50 \mathrm{n}}{ }^{(0)}\right)$ to that of alpha-ray exposure $\left(D_{50 \mathrm{n}}{ }^{(1)}\right)$ for $\mathrm{M}_{1}$ effects, and as the ratio of $D_{8}$ of neutron exposure $\left(D_{8 \mathrm{n}}{ }^{(0)}\right)$ to that of alpha-ray exposure $\left(D_{8 \mathrm{n}}{ }^{(1)}\right)$ for mutation rate:

$$
\begin{aligned}
& \mathrm{BAE}=D_{50 \mathrm{n}}{ }^{(0)} / D_{50 \mathrm{n}}{ }^{(1)} \quad \text { for } \mathrm{M}_{1} \text { effects } \\
& \mathrm{BAE}=D_{8 \mathrm{n}}{ }^{(0)} / D_{8 \mathrm{n}}{ }^{(1)} \quad \text { for mutation rate }
\end{aligned}
$$

Except for number of spikes, with a higher BAE value, the biological effects, including mutation rate, showed nearly equivalent BAEs, ranging from 32.8 for seedling height to 38.1 for seed fertility.

\section{Estimation of RBE for alpha particles and protons}

As shown previously (Ukai et al. 2009a, 2009b), the following relationship holds between the ratio of the $D_{50}$ of gamma-rays to that of thermal neutrons on the one hand and
Mutation rate per cell (\%)

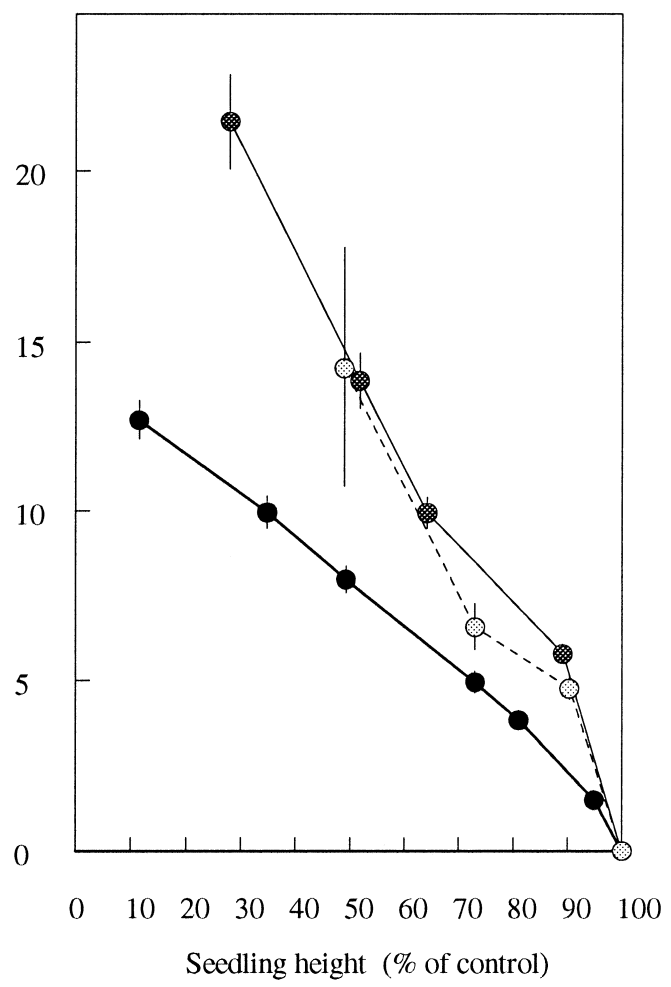

Fig. 2. Mutation rate as a function of seedling height. Solid, heavyshaded, and light-shaded circles stand for exposure of gamma-rays, neutrons and alpha particles.

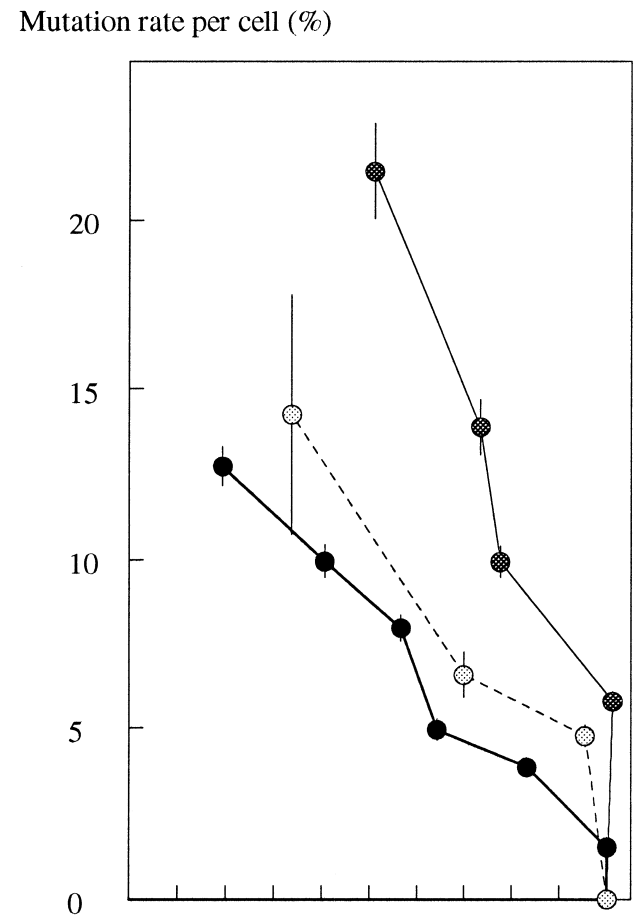

$\begin{array}{lllllllllll}0 & 10 & 20 & 30 & 40 & 50 & 60 & 70 & 80 & 90 & 100\end{array}$

No. of spikes (\% of control)

Fig. 3. Mutation rate as a function of number of spikes per surviving plant. Solid, heavy-shaded, and light-shaded circles stand for exposure of gamma-rays, neutrons and alpha particles. 
Mutation rate per cell (\%)

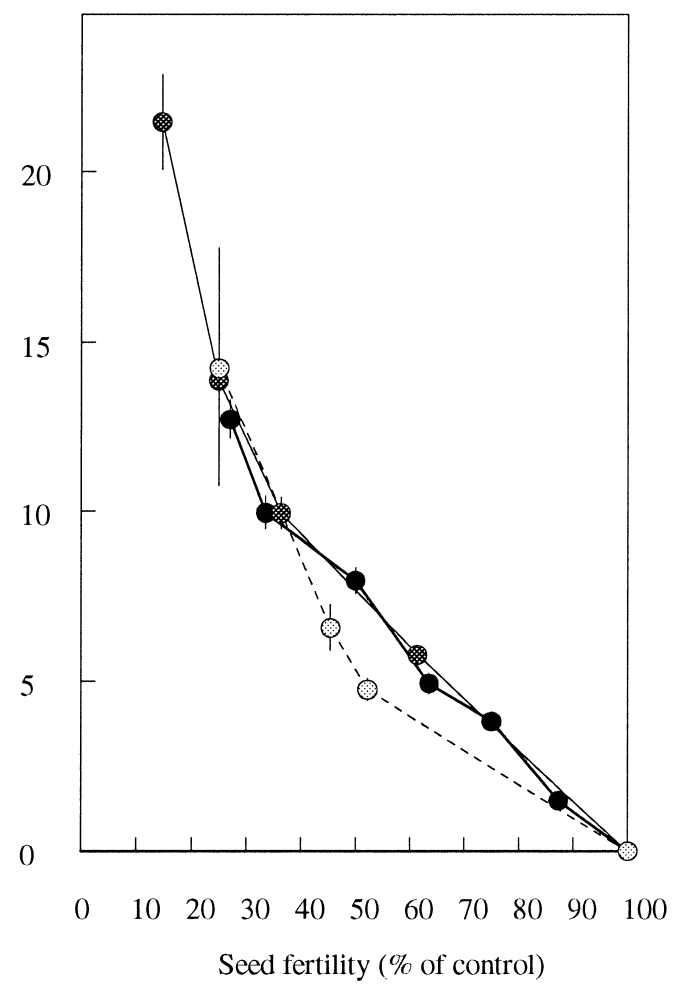

Fig. 4. Mutation rate as a function of seed fertility. Solid, heavyshaded, and light-shaded circles stand for exposure of gamma-rays, neutrons and alpha particles.

RBE of alpha particles and protons on the other:

$$
D_{50 \mathrm{~g}} / D_{50 \mathrm{n}}=\delta+d_{\mathrm{H}}+e_{\mathrm{N}} d_{\mathrm{N}}+e_{\mathrm{B}} d_{\mathrm{B}}
$$

where $D_{50 \mathrm{~g}}$ is the $D_{50}$ in gamma-ray exposure (in Gy); $D_{50 \mathrm{n}}$ is the $D_{50}$ in thermal neutron exposure (in fluence, $\mathrm{n} \mathrm{cm}^{-2}$ ); $\delta$ is the dose of contaminating gamma-rays (in Gy per fluence of neutrons); $d_{\mathrm{H}}, d_{\mathrm{N}}$, and $d_{\mathrm{B}}$ are the neutron energies absorbed by ${ }^{1} \mathrm{H},{ }^{14} \mathrm{~N}$, and ${ }^{10} \mathrm{~B}$, respectively (in Gy per fluence of neutrons); and $e_{\mathrm{N}}$ and $e_{\mathrm{B}}$ are the RBE values of protons from ${ }^{14} \mathrm{~N}(\mathrm{n}, \mathrm{p}){ }^{14} \mathrm{C}$ and alpha particles from ${ }^{10} \mathrm{~B}(\mathrm{n}, \alpha){ }^{7} \mathrm{Li}$, respectively. The RBEs of ${ }^{1} \mathrm{H}$ and contaminating gamma-rays were assumed to equal 1 . Similar relationship holds between the ratio $D_{8 \mathrm{~g}} / D_{8 \mathrm{n}}$ and RBEs for mutation rate.

The value of $\delta$ (in Gy per fluence of neutrons) can be obtained by dosimetry: $10.52 /\left(3.15 \times 10^{9} \times 3600\right)=0.9277$ $\times 10^{-12}$ in the first exposure; and $6.466 /\left(4.03 \times 10^{9} \times 3600\right)$ $=0.4457 \times 10^{-12}$ in the second exposure of thermal neutrons. The $\mathrm{B}$ contents of the embryos of conventional resting seeds and of seeds soaked in $\mathrm{H}_{3}{ }^{10} \mathrm{BO}_{3}$ and the $\mathrm{N}$ and $\mathrm{H}$ contents of the embryos of resting seeds were reported previously (Ukai et al. 2009b). From these contents and the thermal neutron flux applied, the absorbed doses per neutron fluence $\left(d_{\mathrm{B}}, d_{\mathrm{N}}\right.$, and $d_{\mathrm{H}}$ of resting seeds and $d_{\mathrm{B}}$ of ${ }^{10} \mathrm{~B}$-enriched seeds) were calculated as shown in Table 2 of Ukai et al. (2009b). The contents of $\mathrm{N}$ and $\mathrm{H}$ and hence the absorbed doses $\left(d_{\mathrm{N}}\right.$ and $\left.d_{\mathrm{H}}\right)$ do not vary during the boron addition treatment.
Table 3. Half-reduction doses of gamma-rays $\left(D_{50 \mathrm{~g}}\right)$ and thermal neutrons $\left(D_{50 \mathrm{n}}\right)$ for M1 effects, doses which give $8 \%$ of mutation rate per cell $\left(D_{8}\right)$, and boron addition effect (BAE)

\begin{tabular}{|c|c|c|c|c|c|}
\hline Radiation & $\begin{array}{c}\text { Germination } \\
\text { rate }\end{array}$ & $\begin{array}{c}\text { Seedling } \\
\text { height }\end{array}$ & $\begin{array}{c}\text { No. } \\
\text { spikes }\end{array}$ & $\begin{array}{l}\text { Seed } \\
\text { fertility }\end{array}$ & $\begin{array}{c}\text { Mutation } \\
\text { rate }^{a}\end{array}$ \\
\hline \multicolumn{6}{|c|}{$D_{50 \mathrm{~g}}$ for gamma-rays ${ }^{b}$} \\
\hline & 564.5 & 394.0 & 411.6 & 382.2 & 406.7 \\
\hline \multicolumn{6}{|c|}{$D_{50 \mathrm{n}}{ }^{(0)}$ for neutron exposure ${ }^{b}$ (resting seeds) } \\
\hline & 25.5 & 15.3 & 20.1 & 6.94 & 8.36 \\
\hline \multicolumn{6}{|c|}{$D_{50 \mathrm{n}}{ }^{(1)}$ for alpha-radiation $\left({ }^{10} \mathrm{~B}\right.$-enriched seeds $\left.{ }^{b}\right)$} \\
\hline & 0.756 & 0.466 & 0.393 & 0.177 & 0.247 \\
\hline $\mathrm{BAE}$ & 33.7 & 32.8 & 51.1 & 38.1 & 33.8 \\
\hline
\end{tabular}

${ }^{a}$ Dose giving a mutation rate per cell of $8 \%\left(D_{8}\right)$.

${ }^{b}$ Half-reduction dose $\left(\mathrm{M}_{1}\right.$ effects) or dose giving $8 \%$ mutation rate: Gy for gamma-rays, $\times 10^{12} \mathrm{n} \cdot \mathrm{cm}^{-2}$ for thermal neutron exposure of resting seeds and ${ }^{10} \mathrm{~B}$-enriched seeds.

Table 4. Relative biological effectiveness (RBE) of alpha particles and protons

\begin{tabular}{|c|c|c|c|c|c|}
\hline Radiation & $\begin{array}{l}\text { Germination } \\
\text { rate }\end{array}$ & $\begin{array}{c}\text { Seedling } \\
\text { height }\end{array}$ & $\begin{array}{c}\text { No. } \\
\text { spikes }\end{array}$ & $\begin{array}{c}\text { Seed } \\
\text { fertility }\end{array}$ & $\begin{array}{c}\text { Mutation } \\
\text { rate }\end{array}$ \\
\hline \multicolumn{6}{|c|}{ Alpha particles, $e_{\mathrm{B}}$} \\
\hline & 59.1 & 66.8 & 83.7 & 166.8 & 130.3 \\
\hline \multicolumn{6}{|c|}{ Protons, $e_{\mathrm{N}}$} \\
\hline & 46.4 & 54.7 & 40.1 & 118.0 & 106.4 \\
\hline
\end{tabular}

RBE values for alpha particles $\left(e_{\mathrm{B}}\right)$ can be calculated as:

$$
e_{\mathrm{B}}=\left(\left(D_{50 \mathrm{~g}}{ }^{(1)} / D_{50 \mathrm{n}}{ }^{(1)}\right)-\left(D_{50 \mathrm{~g}}{ }^{(0)} / D_{50 \mathrm{n}}{ }^{(0)}\right)\right) /\left(d_{\mathrm{B}}{ }^{(1)}-d_{\mathrm{B}}{ }^{(0)}\right)
$$

where superscripts ( 0 ) and (1) for $d_{\mathrm{B}}$ stand for the value for resting seeds and the ${ }^{10} \mathrm{~B}$-enriched seeds, respectively, and $D_{50 \mathrm{~g}}{ }^{(0)}$ is the $D_{50}$ for a biological effect in gamma-irradiation of resting seeds; $D_{50 \mathrm{~g}}{ }^{(1)}$ for gamma-irradiation of ${ }^{10} \mathrm{~B}$ enriched seeds; $D_{50 \mathrm{n}}{ }^{(0)}$ for neutron exposure of resting seeds; and $D_{50 \mathrm{n}}{ }^{(1)}$ for neutron exposure of ${ }^{10} \mathrm{~B}$-enriched seeds.

The calculated RBEs for the biological effects are shown in Table 4. The values were low for germination rate and seedling height, and number of spikes, and high for seed fertility and mutation rate.

Putting the calculated value of $e_{\mathrm{B}}$ into Eq. (2) gives the value of $\left(\delta+d_{\mathrm{H}}+e_{\mathrm{N}} d_{\mathrm{N}}\right)$ and hence the RBE value of protons $\left(e_{\mathrm{N}}\right)$, as shown in the last row of Table 4 . The values were low for germination rate and seedling height, and number of spikes, and high for seed fertility and mutation rate. RBEs of alpha particles and protons were significantly correlated $(r=0.939, P<0.05)$.

\section{Discussion}

\section{Effectiveness and efficiency of radiation treatments}

Nilan et al. (1965) defined the effectiveness of radiation as the mutation rate in relation to dose, and the efficiency of radiation as the mutation rate in relation to other biological effects induced, usually a measure of damage. In comparisons 
of the utility of different forms of radiation as mutagens, these two definitions should be taken into account. Thus, effectiveness can be measured as RBE for mutation, and efficiency can be evaluated from the relation of mutation rate to the value of an $\mathrm{M}_{1}$ injurious effect (Fig. 1-Fig. 4).

In comparison of efficiency of different radiations, it is important to estimate mutation rate per cell by the frequency of mutants in $\mathrm{M}_{2}$ multiplied by the inverse of expected segregation ratio of mutants. According to Gaul (1960), the mutation rate so estimated is independent of the number of plants per $\mathrm{M}_{2}$ line and the number of initial cells that survived irradiation. On the other hand, the frequency of mutant segregating lines in $\mathrm{M}_{2}$, although it is often used, should not be used as an estimate of mutation rate per cell, since it is equal to the latter if and only if the number of plants per $\mathrm{M}_{2}$ line is infinite and the number of survived initial cells is one i.e. no chimera within $\mathrm{M}_{1}$ spikes.

In mutation breeding, a mutagenic treatment which gives a high maximum mutation rate is usually recommended. Mutation rate per cell at the time of irradiation of seeds or the frequency of mutants in $\mathrm{M}_{2}$ increased almost linearly with increasing total dose. However, increasing the dose simultaneously increased the magnitude of undesirable $M_{1}$ effects, which restricts the maximum mutation rate attainable. Germination rate, number of spikes per plant, number of flowers per spike, and rate of seed fertility in $\mathrm{M}_{1}$ jointly determine the amount of seeds available for the next generation $\left(\mathrm{M}_{2}\right)$, in which mutants are screened. Among these traits, the number of flowers per spike was hardly affected by irradiation (data not shown). So we multiplied the remaining three traits and called the product "index $T$ ". A mutagenic treatment with a lower value of $\mathrm{T}$ gives smaller number of $\mathrm{M}_{2}$ seeds. Beyond a certain limit of $\mathrm{T}, \mathrm{M}_{2}$ seeds sufficient for screening of mutants can hardly be obtained. It may be reasonable to consider that a mutation rate at a very low value of index $\mathrm{T}$, for instance, 0.1 , shows the maximum mutation rate practically attainable.

When mutation rate was expressed as a function of index $\mathrm{T}$, the mutation rate at a given value, especially a low value, of index $\mathrm{T}$ differed between the forms of radiation: highest for neutrons, followed by alpha-radiation, and lowest for gamma-rays (Fig. 5). This means that the maximum mutation rate attainable is lowest for gamma-rays, intermediate for alpha-radiation, and highest for neutrons.

Figure 1 shows that germination rate decreased to as low as $44 \%$ of the control at the highest dose employed. In thermal neutron exposure, however, reduction in germination rate was slight even at the highest dose shown (20.4 Gy). In other words, reduction in germination rate is a limiting factor for elevating mutation rate for gamma-ray exposure, but not for thermal neutron exposure. Summarizing the results in Figures 1, 3, and 4 suggest that in gamma-irradiation, the reduction of germination rate, number of spikes, and seed fertility restricts the maximum mutation rate attainable, whereas in neutron exposure, the decrease of seed fertility is the major factor limiting the maximum mutation rate. In
Mutation rate per cell (\%)

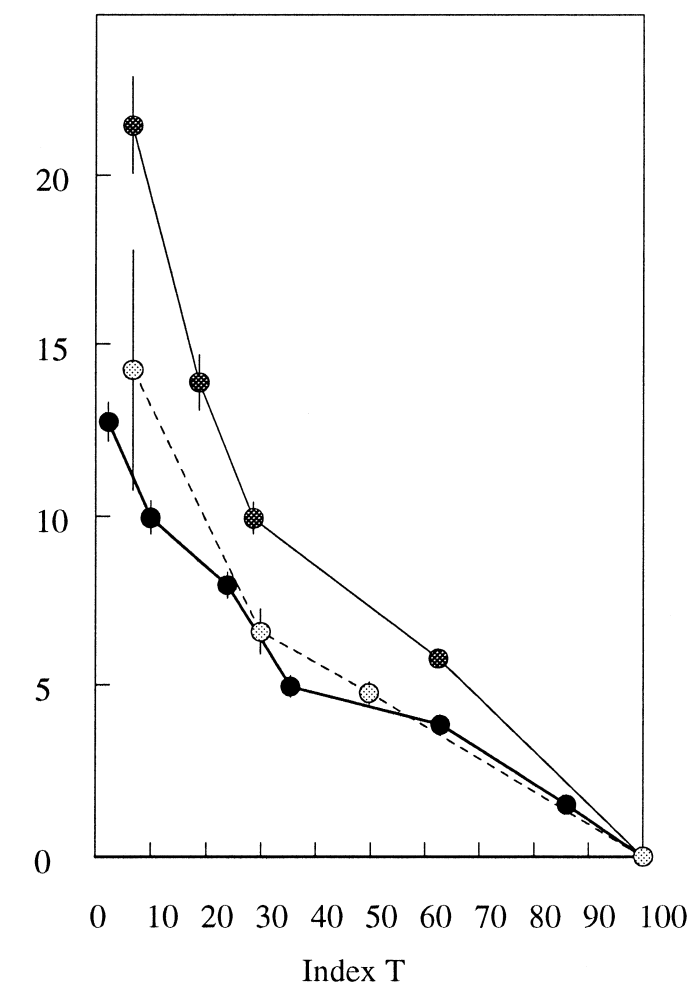

Fig. 5. Mutation rate as a function of index T. Solid, heavy-shaded, and light-shaded circles stand for exposure of gamma-rays, neutrons and alpha particles.

alpha-radiation the reduction of germination rate and the number of spikes determine the maximum mutation rate.

It is laborious and time-consuming to reproducibly determine mutation rates in $\mathrm{M}_{2}$ after a mutagenic treatment, because the frequency of mutants in $\mathrm{M}_{2}$ is usually very low and a survey over a large population of $\mathrm{M}_{2}$ plants is required. Hence, an $\mathrm{M}_{1}$ biological effect (for instance, on seedling height) has often been used as a convenient criterion representing the magnitude of general radiation effects. However, if the efficiency of radiation for mutation induction differs between forms of radiation, this method loses some of its utility. In fact, the relationship of seedling height to mutation rate varied between gamma-rays, neutrons, and alpharadiation (Fig. 2): an increase of mutation rate was accompanied by much more reduction of seedling height by gammarays than by neutrons. This suggests that seedling height results cannot always be used directly, in a quantitative sense, as a proxy for mutation rate in comparisons of the utility of different forms of radiation.

\section{$B A E$ of $M_{1}$ effects and mutation rate}

BAE was very high for all biological effects investigated, ranging from 32.8 for seedling height to 51.1 for number of spikes. Except for number of spikes, BAE values were nearly equivalent among effects, including mutation rate. This result is inconsistent with that of Ecochard and de Nettancourt (1969), who reported BAEs that were much 
smaller than ours and that varied with biological effects from1.040 (fruit set) to 1.652 (chlorophyll mutations).

The RBE values of alpha particles and protons for seedling height in the present study (66.8 and 54.7) were a slightly higher than those we reported previously (55.0 and 48.7: Ukai et al. 2009b). This was mainly due to a slightly higher value of $\mathrm{D}_{50}$ for gamma-rays in the present experiment, which may comes from variations in physiological conditions of seeds among harvest years.

The BAE for mutation rate was 33.8. In other words, boron addition increased the effectiveness of thermal neutrons (sensu Nilan et al. 1964) to 33.8 times. However, the same treatment did not increase the efficiency of thermal neutrons at all. The mutation rate at a given value of an $\mathrm{M}_{1}$ effect (\% of control) by alpha-radiation was equal to or slightly lower than that by neutrons in seedling height and seed fertility (Fig. 2 and Fig. 4), and much lower in germination rate and number of spikes (Fig. 1 and Fig. 3). Moreover, the maximum mutation rate attainable by alpha-radiation was lower than that provided by neutrons, as described above.

Although ${ }^{10} \mathrm{~B}$ addition of seed gave no advantage in the efficiency of neutron exposure and the maximum mutation rate attainable, it has two merits from the viewpoint of mutation breeding. First, it changes the chlorophyll mutation spectrum. The result is consistent with that of Nakai and Saito (1976) in rice, and suggests the possibility of obtaining mutations which are not obtainable by neutron exposure of non- ${ }^{10} \mathrm{~B}$ enriched seeds. Second, the large increase in mutation rate per neuron flux after ${ }^{10} \mathrm{~B}$ addition dramatically decreases the neutron fluence required for exposure of plant materials, and thus the time of occupation in the deuteron facility. For instance, for breeding purposes, a fluence of $1 \times 10^{13}$ to $2 \times 10^{13} \mathrm{n} \mathrm{cm}^{-2}$ is required for exposure of normal barley seeds, which takes 1 to $2 \mathrm{~h}$ under a thermal neutron flux of $3 \times 10^{9} \mathrm{n} \mathrm{cm}^{-2} \mathrm{~s}^{-1}$, whereas only 2 to 4 min was enough for exposure of ${ }^{10} \mathrm{~B}$-enriched seeds. Shortening of the time required for exposure in turn increases the amount of seeds which can be irradiated in a given time. In addition, shortening of the exposure time decreases the residual activity of the irradiated seeds, which is advantageous for handling and transportation of the irradiated materials after exposure.

\section{RBE of alpha particles and protons}

By summarizing results for alpha particles, protons, and carbon ions, Nikjoo et al. (1999) showed that RBE of these particles for induction of double-strand breaks in a mammalian cell system and for mutation induction in Drosophila melanogaster and Escherichia coli was $<6$, and close to 1 in most cases. Very little information is available on RBE for mutation rate in plants, but values are much higher than these. Matsumura et al. (1963) showed in diploid wheat (Triticum monococcum) that RBE for chlorophyll mutation rate ranged from 27 to 56, depending on the borate concentration used. They excluded the RBE of 56 obtained for $0.1 \%$ borax as an extreme case and provisionally claimed that RBE was $29 \pm 10$. Ikushima (1972) showed that RBEs for mutation rate were 9.18 in $T$. monococcum, 4.73 in Triticum durum, and 14.8 in Triticum aestivum. However, these results were not conclusive, because the authors did not analyze the B content of the seed embryos, and instead used a value calculated on the assumptions of free entrance of B into seeds and homogeneous distribution of B atoms within seeds. Our recent report showed that these two assumptions are not valid (Ukai et al. 2009b). In contrast, RBE for mutation rate obtained in the present study was 130.3 , much higher than RBEs so far reported in plants.

$\mathrm{RBE}$ of alpha particles differed among $\mathrm{M}_{1}$ effects and mutation rate. Thus, $M_{1}$ effects are not necessarily accurate as a proxy for mutation rate in comparisons of different types of radiation. Similar differences among biological effects have been reported by other researchers. In a study of thermal neutron-induced metaphase chromosome aberrations in Nigella damascena, Moutschen et al. (1968) found that RBE of alpha particles was about three times as high for one-hit aberrations as for two-hit aberrations. Ikushima (1972) showed that RBE was 1.41 for seedling height, 3.60 for seed set, and 4.73 to 14.8 for chlorophyll mutation rates in wheat.

The ratio of RBE of alpha particles for mutation rate to RBE for an $\mathrm{M}_{1}$ effect can be divided into sub-components. Combining Eqs. (1) and (3) gives:

$$
\begin{aligned}
& e_{\mathrm{B}}{ }^{(\mathrm{R})}=\left(\left(D_{50 \mathrm{~g}}{ }^{(\mathrm{R} 1)} / D_{50 \mathrm{n}}{ }^{(\mathrm{R} 1)}\right)-\left(D_{50 \mathrm{~g}}{ }^{(\mathrm{R} 0)} / D_{50 \mathrm{n}}{ }^{(\mathrm{R} 0)}\right)\right) /\left(d_{\mathrm{B}}{ }^{(1)}-d_{\mathrm{B}}{ }^{(0)}\right) \\
& =\left(\left(\mathrm{BAE}^{\mathrm{(R})} \cdot D_{50 \mathrm{~g}}{ }^{\mathrm{R} 1)} / D_{50 \mathrm{n}}{ }^{(\mathrm{R} 0)}\right)\right. \\
& \left.-\left(D_{50 \mathrm{~g}}{ }^{(\mathrm{R} 0)} / D_{50 \mathrm{n}}{ }^{(\mathrm{R} 0)}\right)\right) /\left(d_{\mathrm{B}}{ }^{(1)}-d_{\mathrm{B}}{ }^{(0)}\right)
\end{aligned}
$$

where $\mathrm{R}$ stands for an $\mathrm{M}_{1}$ effect and 0 and 1 stand for the resting seeds and the ${ }^{10} \mathrm{~B}$-enriched seeds, respectively. As reported previously (Ukai et al. 2009b), the sensitivity to gamma-rays does not change with boron addition of $1600 \mu \mathrm{g} \cdot \mathrm{g}^{-1}$, and hence it can be assumed that $D_{50 \mathrm{~g}}{ }^{\mathrm{R} 1))}$ $=D_{50 \mathrm{~g}}{ }^{(\mathrm{R} 0))}=D_{50 \mathrm{~g}}{ }^{\mathrm{R})}$, where $D_{50 \mathrm{~g}}{ }^{(\mathrm{R})}$ represents the mean of $D_{50 \mathrm{~g}}{ }^{(\mathrm{R} 0)}$ and $D_{50 \mathrm{~g}}{ }^{(\mathrm{R} 1)}$. Therefore:

$$
e_{\mathrm{B}}{ }^{(\mathrm{R}))}=\left(D_{50 \mathrm{~g}}{ }^{(\mathrm{R})} / D_{50 \mathrm{n}}{ }^{(\mathrm{R} 0)}\right)\left(\mathrm{BAE}^{(\mathrm{R})}-1\right) /\left(d_{\mathrm{B}}{ }^{(1)}-d_{\mathrm{B}}{ }^{(0)}\right)
$$

A similar equation holds for mutation rate:

$$
e_{\mathrm{B}}^{(\mathrm{M})}=\left(D_{8 \mathrm{~g}}{ }^{(\mathrm{M})} / D_{8 \mathrm{n}}{ }^{(\mathrm{M} 0)}\right)\left(\mathrm{BAE}^{(\mathrm{M})}-1\right) /\left(d_{\mathrm{B}}^{(1)}-d_{\mathrm{B}}{ }^{(0)}\right)
$$

where $\mathrm{M}$ represents mutation rate, and $D_{8 \mathrm{~g}}{ }^{(\mathrm{M})}$ and $D_{8 \mathrm{n}}{ }^{(\mathrm{M} 0)}$ dose which gives $8 \%$ of mutation rate per cell in gamma-ray and neutron exposure on resting seeds. Because the $B A E^{(\mathrm{R})}$ and $\mathrm{BAE}^{(\mathrm{M})}$ are nearly equal and hence $\left(\mathrm{BAE}^{(\mathrm{M})}-1\right)$ / $\left(\mathrm{BAE}^{(\mathrm{R})}-1\right) \approx 1$ except for the number of spikes, from Eqs. (4a) and (4b), the ratio of RBE of alpha particles for mutation rate to $\mathrm{RBE}$ of an $\mathrm{M}_{1}$ injury is given by:

$$
\begin{aligned}
& e_{\mathrm{B}}{ }^{(\mathrm{M})} / e_{\mathrm{B}}{ }^{(\mathrm{R})}=\left(D_{8 \mathrm{~g}}{ }^{(\mathrm{M})} / D_{50 \mathrm{~g}}{ }^{(\mathrm{R})}\right)\left(D_{50 \mathrm{n}}{ }^{(\mathrm{R} 0)} / D_{8 \mathrm{n}}{ }^{(\mathrm{M} 0)}\right) \\
& \left(\left(\mathrm{BAE}^{(\mathrm{M})}-1\right) /\left(\mathrm{BAE}^{(\mathrm{R})}-1\right)\right) \\
& \approx\left(D_{8 \mathrm{~g}}{ }^{(\mathrm{M})} / D_{8 \mathrm{n}}{ }^{(\mathrm{M} 0)}\right) /\left(D_{50 \mathrm{~g}}{ }^{(\mathrm{R})} / D_{50 \mathrm{n}}{ }^{(\mathrm{R} 0)}\right)
\end{aligned}
$$

Thus, the ratio of RBE for mutation rate to that for an $\mathrm{M}_{1}$ effect can be ascribed to three factors: ratio of $D_{50 \mathrm{~g}}{ }^{\mathrm{M})}$ to $D_{50 \mathrm{~g}}{ }^{(\mathrm{R})}$, ratio of $D_{50 \mathrm{n}}{ }^{(\mathrm{R} 0)}$ to $D_{50 \mathrm{n}}{ }^{\mathrm{(} 0)}$ for non-enriched seeds, and ratio of $\left(\left(\mathrm{BAE}^{(\mathrm{M})}-1\right)\right.$ to $\left(\mathrm{BAE}^{(\mathrm{R})}-1\right)$. Since BAE did 
not vary much between mutation rate and $M_{1}$ effects (except for number of spikes), the ratio of RBE depends mostly on the first two ratios. Or, $e_{\mathrm{B}}{ }^{(\mathrm{M})} / e_{\mathrm{B}}{ }^{(\mathrm{R})} \approx\left[D_{50 \mathrm{~g}}{ }^{(\mathrm{M})} / D_{50 \mathrm{n}}{ }^{(\mathrm{M} 0)}\right.$ (in $\left.\mathrm{Gy} \cdot \mathrm{n}^{-1} \cdot \mathrm{cm}^{2}\right)$ for mutation rate $] /\left[D_{50 \mathrm{~g}}{ }^{(\mathrm{R})} / D_{50 \mathrm{n}}{ }^{\mathrm{R} 0)}\right.$ for an $\mathrm{M}_{1}$ effect].

Larsson and Kihlman (1960) showed that RBE of an external $185 \mathrm{MeV}$ proton beam from a synchrocyclotron for chromosome aberrations was as low as 0.7 . Smith et al. (1970) exposed seeds of a genetic stock of maize heterozygous at the yellow green locus, $Y g 2 / y g 2$, to $28 \mathrm{GeV}$ external proton beam from the Alternating Gradient Synchrotron and found that RBE for the number of $y g 2$ sectors on leaves was 3.5 to 5.2. However, RBE of protons in thermal neutron exposure of plant materials had never previously been evaluated as far as we are aware. RBE of protons for mutation rate was very high (106.4). As did RBE of alpha particles, RBE of protons differed between biological effects, being low for germination rate, seedling height, and number of spikes, and high for seed fertility and mutation rate. RBEs of alpha particles and protons were significantly correlated $(r=0.939$, $P<0.05)$.

Why the RBEs differed between biological criteria is not clear, but it may be related to induced cellular damage. Two major types of cellular events lead ultimately to these $\mathrm{M}_{1}$ effects: the arrest of cell division (Maity et al. 1994) and chromosome aberrations. In the comparison of radiosensitivity of rice cultivars, Ukai (1968) showed that $D_{50}$ for the number of dividing cells at the first mitosis after germination of root tip meristem was highly significantly correlated with $D_{50}$ for seedling height. On the other hand, Ekberg (1969) reported that most seed sterility induced by gamma-ray and neutron exposure derived from chromosome aberrations, particularly translocations and inversions. The reductions in germination rate, seedling height, and number of spikes (which had lower values of RBE) are all related to the arrest of cell division during and after germination in the shoot meristem, whereas seed sterility and mutation (which had higher values of RBE) are caused by damage to heritable elements, gross damage to chromosomes versus alterations in DNA sequences, respectively.

Ishida et al. (2006) reported that RBE of fast neutrons was dose-dependent in mouse. RBE of neutrons for the induction of neuronal apoptosis in the dose range of 0.5 to 1.5 Gy was about 3 , but within the lower dose range of 0.02 to $0.1 \mathrm{~Gy}$ was 9.8 . We compared the effectiveness of the different forms of radiation for mutation rate at the $8 \%$ point. When doses giving mutation rates of $2 \%, 4 \%$, and $12 \%$ were estimated from dose-response curves and used in the calculation of RBE, RBE of alpha particles was 175.3, 127.0, and 135.1 , and RBE of protons was $120.6,107.8$, and 104.7, respectively. These values are near the values obtained at the $8 \%$ mutation rate. The fluctuations in RBE values with the cut-off mutation rate were relatively small, though at the lowest rate of mutation ( $2 \%)$, RBEs of both alpha particles and protons were a little larger than those at the higher rates of mutation.
Yoshikawa et al. (1998) showed in a study of the RBELET relationship in Drosophila that $m w h$ wing hair mutations showed a strong dependence on LET of carbon ions, yet the $w^{i}$ eye-color revertant mutation showed no dependency on LET. The chlorophyll mutation rates we recorded here are totals of mutations at a large number of loci relating to chlorophyll formation. Further studies are needed to see whether RBEs of alpha particles and protons differs between chlorophyll mutation and other mutations, especially useful ones.

RBE of alpha-particles and protons may differ depending on the biological materials, treatment method, and energy of particles emitted from the source. High RBE values of alpha particles and protons obtained here are confined to the internal exposure of initial cells of seed to alpha particles and protons that were emitted from neutron capture reaction of ${ }^{10} \mathrm{~B}$ and ${ }^{14} \mathrm{~N}$, respectively.

Alpha particles emitted from capture reaction of ${ }^{10} \mathrm{~B}$ has low energy $(2.4 \mathrm{MeV})$ and a very short path of about $13.5 \mu \mathrm{m}$ in tissues (Conger and Giles 1950). Hence, unlike gamma-rays and X-rays, external exposure of seeds and plants to alpha-particles is not practically effective. Moreover, such short path length leads to the uneven radiation effects on DNA and chromosomes within cells, if the distribution of the boron elements in cells is localized (Ukai et al. 2009b). Alpha particles with a slightly higher energy $(5 \mathrm{MeV})$ are emitted from radionucleids such as Am-241, plutonium-238 and plutonium-239. Cultured cells are externally irradiated with these types of alpha particles in human cells (Raju and Jett 1974, Barnhart and Cox 1979, Purrot et al. 1980) and Chinese hamster cells (Hall et al. 1984). However, such an experiment has not been attempted for mutation breeding in plants, since regeneration of a sufficiently large number of $\mathrm{M}_{1}$ plants from irradiated cultured cells is very difficult.

Protons emitted from capture reaction of ${ }^{14} \mathrm{~N}$ also have a low energy $(0.63 \mathrm{MeV})$ and a path length of $10 \mu \mathrm{m}$. Unlike alpha particles, external exposure of plant materials to protons of high energy has been performed since early days of radiation biology research in plants, as described above. However, external proton exposure as a mutagen in mutation breeding has not so far been reported, although it has been extensively utilized in radiation therapy (Suit and Urie 1992).

\section{Acknowledgments}

Thanks are due to staff members of the Research Reactor Institute, Kyoto University, particularly Dr. Tadatoshi Kikuchi, for their great help in performing the neutron exposures and dosimetry.

\section{Literature Cited}

Barendsen,G.W. (1994) The relationships between RBE and LET for different types of lethal damage in mammalian cells: biophysical and molecular mechanisms. Rad. Res. 139: 257-270. 
Barnhart,B.J. and S.H.Cox (1979) Mutagenicity of $4.4 \mathrm{MeV} \alpha$ particles emitted by plutonium-238. Radiat. Res. 80: 542-548.

Bender,M.A. (1970) Neutron-induced genetic effects: a review. Rad. Bot. 10: 225-247.

Conger,A.D. and N.H.Giles (1950) The cytogenetic effect of slow neutrons. Genetics 35: 397-419.

Davis,M.A., J.B.Little, K.M.M.S.Ayyangar and A.R.Reddy (1970) Relative biological effectiveness of the ${ }^{10} \mathrm{~B}(\mathrm{n}, \alpha){ }^{7} \mathrm{Li}$ reaction in HeLa cells. Rad. Res. 43: 534-553.

Ecochard, R. and D.deNettancourt (1969) Boron dependence of the genetic radiosensitivity during thermal neutron irradiation. Rad. Bot. 9: 213-219.

Ecochard,R. and W.F.Oosterheert (1966) On the role of boron in the thermal neutron sensitivity of plants. Int. J. Rad. Biol. 11:385-387.

Ekberg,I. (1969) Different types of sterility induced in barley by ionizing radiations and chemical mutagens. Hereditas 63: 257-278.

Gaul,H. (1960) Critical analysis of the methods for determining the mutation frequency after seed treatment with mutagens. Genet. Agrar. 12: 297-318.

Goodhead,D.T. (1999) Mechanisms for the biological effectiveness of high-LET radiations. J. Radiat. Res. 40: (Suppl.) 1-13.

Hall,E.J., W.Gross, R.F.Dvorak, A.M.Kellerer and H.H.Rossi (1984) Survival curves and age response functions for Chinese hamster cells exposed to X-rays and high-LET alpha particles. Radiat. Res. 52: 88-89.

Ichikawa, S. (1975) The biological effects of heavy particles from the nuclear reaction of ${ }^{10} \mathrm{~B}(\mathrm{n}, \alpha)^{7} \mathrm{Li}$ in diploid wheat seeds containing widely different ${ }^{10} \mathrm{~B}$ contents. Ann. Rep. Res. Reactor Inst. Kyoto Univ. 8: 32-43.

Ikushima,T. (1972) Relative biological effectiveness of heavy particles from the reaction ${ }^{10} \mathrm{~B}(\mathrm{n}, \alpha)^{7} \mathrm{Li}$ for cytogenetic effects in a ploidy series of the genus Triticum. Jpn. J. Genet. 47: 401-410.

Ishida, Y., Y.Ohmachi, Y.Nakata, T.Hiraoka, T.Hamano, S.Fushiki and T.Ogiu (2006) Dose-response and large relative biological effectiveness of fast neutrons with regard to mouse fetal cerebral neutron apoptosis. J. Radiat. Res. 47: 41-47.

Larsson, B. and B.A.Kihlman (1960) Chromosome aberrations following irradiation with high-energy protons and their secondary radiation: a study of dose distribution and biological efficiency using root-tips of Vicia faba and Allium cepa. Int. J. Rad. Biol. 2: 8-19.

MacKey,J. (1951) Neutron and X-ray experiments in barley. Hereditas 37: $421-464$.

Maity,A., W.G.McKenna and R.J.Muschel (1994) The molecular basis for cell cycle delays following ionizing radiation: a review. Radiother. Oncol. 31: 1-13.

Matsumura,S., S.Kondo and T.Mabuchi (1963) Radiation genetics in wheat VIII. The RBE of heavy particles from ${ }^{10} \mathrm{~B}(\mathrm{n}, \alpha)^{7} \mathrm{Li}$ reaction for cytogenetic effects in einkorn wheat. Rad. Bot. 3: 29-40.

Moutschen, J.M.Moutschen-Dahmen, R.Woodley and J.Archambeau (1968) The RBE of heavy particles from the reaction ${ }^{10} \mathrm{~B}(\mathrm{n}, \alpha)^{7} \mathrm{Li}$ for chromosome aberrations in Nigella damascene L. Rad. Res. 34: 488-500.

Myttenaere,C., Ph.Bourdeau, G.Helcke and M.Masset (1965) Radiosensitivity of rice seed in relation to water content and free radicals. Rad. Bot. 5: 443-451.

Nakai,H. and M.Saito (1976) The contribution of boron to radiobiological effects of thermal neutrons in rice. Environ. Exp. Bot. 16: 267-275.

Nikjoo,H., R.J.Munson and B.A.Bridges (1999) RBE-LET relationships in mutagenesis by ionizing radiation. J. Radiat. Res. 40: (Suppl.) 85-105.

Nilan, R.A., C.F.Conzak, J.Wagner and R.R.Legault (1965) Effectiveness and efficiency of radiations for inducing genetic and cytogenetic changes. In: "The Use of Induced Mutations in Plant Breeding", Pergamon Press, Oxford. pp. 71-89.

Purrot,R.J., A.A.Edwards, D.C.Lloyd and J.W.Stather (1980) The induction of chromosome aberrations in human lymphocytes by in vitro irradiation with $\alpha$-particles from plutonium-239. Int. J. Radiat. Biol. 38: 277-284.

Raju,M.R. and J.H.Jett (1974) RBE and OER variations of mixtures of plutonium alpha particles and X-rays for damage to human kidney cells (T-1). Radiat. Res. 60: 473-481.

Smith, H.H., R.G. Woodley, A.Maschke, N.C.Combatti and P.J. McNulty (1970) Relative cytogenetic effectiveness of $28 \mathrm{GeV}$ protons. Radia. Res. 57: 59-66.

Suit,H. and M.Urie (1992) Proton beams in radiation therapy. J. Natl. Cancer Res. Inst. 84: 155-164.

Ukai,Y. (1968) Studies on varietal differences in radiosensitivity in rice. III. Radiosensitivity with respect to the reduction in the number of dividing cells and the occurrence of chromosome bridges. Jpn. J. Breed. 18: 211-228.

Ukai,Y. (1986) Maximum mutation frequency in gamma-ray and thermal neutron exposures in barley. Gamma Field Symp. 25: 55-52.

Ukai,Y. (2006) Effectiveness and efficiency of mutagenic treatments. Gamma Field Symposia 45: 1-14.

Ukai,Y., I.Ymaguchi and H.Takaki (2009a) Moisture content of seeds affects relative biological effectiveness of alpha particles but not protons in thermal neutron exposure. Breed. Sci. 59: 129-137.

Ukai,Y., A.Yamashita and H.Takaki (2009b) Simultaneous estimation of relative biological effectiveness of alpha particles and protons in thermal neutron exposure of barley (Hordeum vulgare L.) seeds. Breed. Sci. 59: 187-193.

Yoshikawa,I., T.Takatsuji, M.Hoshi, J.Takada, T.Kanai, Y.Furusawa, H.Nikjoo and M.Ikenaga (1998) The relative biological effectiveness of accelerated carbon ions with different LET for inducing mitotic crossing over and intragenic reversion of the white-ivory allele in Drosophila larvae. Int. J. Radiat. Biol. 74: 239-248.

Yoshikawa,I., T.Takatsuji, M.Nagano, J.Takada, S.Endo and M. Hoshi (1999) RBE-LET relationships of high-LET radiations in Drosophila mutations. J. Radiat. Res. 40: (Suppl.) 106-116. 